\title{
Analysis of the histomorphologic profile of invasive cutaneous squamous cell carcinoma from 2002 to 2011 in a pathology laboratory in the region of Campos Gerais, Brazil
}

\author{
Fernanda Magri de Souza ${ }^{1}$ \\ Mário Rodrigues Montemór Netto ${ }^{1,2}$
}

\author{
Eloina Do Rocio Valenga Baroni ${ }^{1,2}$
}

DOI: http://dx.doi.org/10.1590/abd1806-4841.20174691

\begin{abstract}
Squamous cell carcinoma is the second most common type of malignant skin cancer. It is also quite aggressive. The increasing incidence of the disease can be altered given its connection with sun exposure. The aim of this study was to establish the clinical and histomorphological profile of squamous cell carcinoma in the region of Campos Gerais, State of Paraná, Brazil and analyze and compare the features of the disease found in the literature. We conducted a cross-sectional descriptive study in a pathology laboratory with selected invasive cutaneous squamous cell carcinoma reports issued after excisional biopsy from January 2002 to December 2011. We selected 374 cases of head and neck SCC, mean age 71.53 years, with a predominance of male patients, moderate degree of histological differentiation, Clark level IV, and absence of perineural, neural, or angiolymphatic invasions. Our results differ on some points from those found in the literature.
\end{abstract}

Keywords: Carcinoma, squamous cell; Dermatology; Pathology

\section{INTRODUCTION}

The increasing incidence of cutaneous squamous cell carcinoma (CSCC) is a worldwide trend. ${ }^{1,2}$ According to estimates from the Brazilian National Cancer Institute, in 2015, non-melanoma skin cancer was responsible for $31.59 \%$ of the malignancies diagnosed in the country. ${ }^{3}$ In Paraná state, a region where skin cancer rates are higher than the national average, figures indicate 129.88 new cases of non-melanoma skin cancer per 100,000 men and 80.64 new cases per 100,000 women. $^{3}$

SCC corresponds to $20 \%$ of non-melanoma skin cancer cases worldwide. Although less common than basal cell carcinoma (BCC), SCC is usually associated with aggressive behavior. ${ }^{1,2,4}$ It is characterized by atypical local invasive squamous cell proliferation and differentiation with metastasis reported in $4-5 \%$ of cases. ${ }^{3,5}$

Skin cancer development is significantly related to chronic sun exposure, which is especially caused by ultraviolet $B$ rays. ${ }^{1,2,46}$ The mechanism involves the production of thymine dimers in the TP53 gene, a tumor suppressor that contributes to DNA mutations and oncogenesis. ${ }^{2,7}$ This association justifies the characterization of actinic keratosis as a precursor lesion and its higher prevalence among older adults. ${ }^{1,6,7}$
Reduced skin pigmentation is considered a risk factor. ${ }^{1,2,4,6}$ The prevalence of people with light skin combined with high exposure to ultraviolet radiation may be responsible for the high incidence of SCC in the southern region of Brazil. ${ }^{1,3,7}$ Additional risk factors include: family history, occupational exposure, and chronic inflammatory skin diseases. ${ }^{1-4,6}$

Diagnosis, treatment, and patient prognosis are established by histopathological analysis. The different histomorphological presentations of SCC are related to the patient's prognosis and define lesion behavior. ${ }^{2,5,8}$ Parameters to be evaluated include: anatomical site, lesion size, depth of invasion, histological differentiation, as well as perineural, neural, and angiolymphatic invasions. ${ }^{2,5,8,9}$

Considering the importance of CSCC as a public health problem, this study aims to establish its epidemiological and histomorphological features in the Campos Gerais region. Based on the results obtained from our study, a profile of the disease in the region could be described, which could be extended to southern Brazil, given the similarities and particularities among the populations.

Received on 04.05.2015

Approved by the Advisory Board and accepted for publication on 13.07.2015

Work performed at the Department of Medicine at Universidade Estadual de Ponta Grossa (UEPG) and Patologia Médica de Ponta Grossa Ltda - Ponta Grossa (PR), Brazil.

Financial Support: None.

Conflict of Interests: None.

Departament of Medicine - Universidade Estadual de Ponta Grossa (UEPG) - Ponta Grossa (PR), Brazil.

Private clinic - Ponta Grossa (PR), Brazil.

(O2017 by Anais Brasileiros de Dermatologia 


\section{METHODS}

We conducted a retrospective cross-sectional study of anatomopathological reports diagnosing cutaneous squamous cell carcinoma in a reference laboratory in Ponta Grossa, Campos Gerais region, Paraná, Brazil, from January 2002 to December 2011.

We obtained the reports for our study directly from the database containing the anatomopathological exams performed during the period described. All biopsies were prepared according to conventional histological techniques and classified according to the College of American Pathologists protocol for the examination of cutaneous neoplasms. ${ }^{9}$

We considered only pathological reports issued after excisional biopsy with positive results for invasive cutaneous squamous cell carcinoma. Incisional biopsies were excluded for not allowing a consistent assessment to determine the histomorphological profile of the neoplasia. Carcinoma in situ and its variants, such as Bowen's disease, were not included because they have a different histomorphological pattern when compared to the invasive variant. Given the structural variations and the impact of risk factors in its etiology, samples from the semi-mucosa and lower and upper lip mucosa were disregarded.

We selected 374 pathological reports. Using Microsoft Excel 2010 software, we created a database containing relevant information to determine the histomorphology of cutaneous squamous cell carcinoma. The following parameters were considered: histologic grading; Clark level; presence of nuclear pleomorphism; stromal desmoplasia; peritumoral lymphoplasmacytic infiltration; neural, perineural, and angiolymphatic invasion; and residual disease at resection margins. We also collected lesion and patient features: sex, age, skin color, clinical hypothesis, anatomical site, size, and color.

Our project was approved by the Research Ethics Committee of the State University of Ponta Grossa.

\section{RESULTS}

We found 3,215 anatomopathological exams reporting malignant cutaneous neoplasms. BCC was the most prevalent, responsible for 2,373 cases (73.8\%); SCC accounted for 569 cases $(17.7 \%)$; and melanoma, 184 cases (5.7\%).

Of the 569 reports of CSCC, 103 were related to SCC in situ and 92 were incisional biopsy products. After exclusion of these cases, we set a sample of 374 cases. 373 discriminated the gender of the patient: 178 female patients (47.7\%) and 195 male patients $(52.3 \%)$. The age was specified in 340 exams. The prevalent age group ranged from $71-80$ years, equivalent to $35.7 \%$ of cases (Graph 1 ). The average age was 71 , with a minimum age of 20 years and a maximum age of 98 years.

The predominance of people with lighter skin color was observed in the study because the entire sample was composed of light-skinned individuals.

Our study revealed a predilection for sun-exposed areas. Of the 351 records that specified the anatomic site of the lesions, 221 reported location on the head and neck (63\%), 71, upper limb $(20.2 \%)$, 33 , lower limb (9.4\%), and 26, trunk (7.4\%). The most affected areas included face (20\%), nose (15\%), ear (14\%), and the scalp (14\%).

The working diagnosis was present in 334 reports prior to biopsy. The propositions found in the evaluated reports were grouped into three classes: neoplastic diseases (311 examinations - 93.1\%), degenerative/inflammatory diseases (9 examinations $2.7 \%$ ) and infectious diseases ( 2 examinations $-0.9 \%$ ). In some cases, the hypothesis was a combination of diseases: neoplastic or degenerative/inflammatory diseases $(10$ cases $-3.0 \%)$ and neoplastic or infectious diseases ( 2 cases $-0.95 \%$ ).

The 262 cases of suspected neoplasm differentiated benign from malignant occurrences: 260 reports $(99.2 \%)$ of suspected malignant neoplasm and only $2(0.8 \%)$ of benign neoplasm. Among the malignant hypotheses, 199 examinations specified the subtype: 147 suspected BCC (73.9\%) and 52, SCC (26.1\%).

The colors of the lesions varied broadly, from brown (200 cases, $53.5 \%$ ) to white (145 cases, $38.8 \%$ ) and other colors (39 cases). Macroscopic evaluation of the lesion size revealed an average of $1.57 \mathrm{~cm}$ on the longest axis, with a minimum variation of $0.1 \mathrm{~cm}$ and a maximum of $9 \mathrm{~cm}$. There was a prevalence of lesions smaller than $4 \mathrm{~cm}$ on the longest axis ( 348 cases $-93 \%$ ).

Histomorphological evaluation revealed the predominance of moderately to well-differentiated tumors. We found moderately differentiated tumors (Broder's grade II) in 200 reports (53.5\%), well differentiated (Broder's grade I) in 146 (39\%), and poorly differentiated (Broder's grade III) in 28 (7.5\%) (Table 1).

The depth was calculated with Clark's level of invasion. In our study, grade IV was detected in 282 cases $(75.4 \%)$, grade $\mathrm{V}$ in 66 (18.9\%), grade III in $16(4.3 \%)$, and grade II in $9(2.4 \%)$ (Table 1$)$.

Stromal desmoplasia, nuclear pleomorphism, and lymphocytic infiltration were present in most samples to varying degrees: mild, moderate, and severe. We observed stromal desmoplasia in 270 cases, which was mild in $66.3 \%$ of cases, moderate in $28.1 \%$, and severe in $5.6 \%$. We observed nuclear pleomorphism in 281 cases, which was moderate in $74.1 \%$ of cases, severe in $17.4 \%$, and mild in $8.5 \%$. We observed lymphocytic infiltration in 291 cases, which was mild in $43.3 \%$ of cases, moderate in $40.9 \%$, and severe in $15.8 \%$. (Table 1)

Resection margins - characterized as free or compromised - were subdivided into lateral and deep. Lateral resection margins

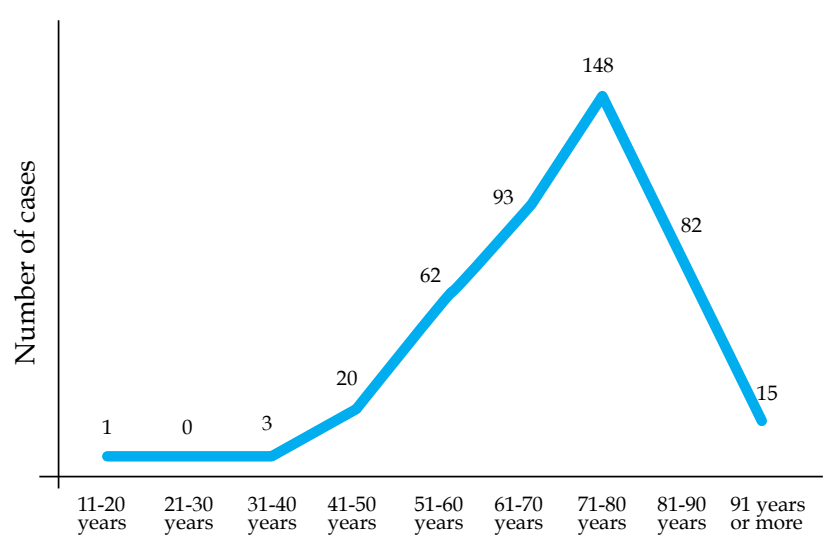

Graph 1: Age distribution of cutaneous squamous cell carcinoma in Campos Gerais - PR (2002-2011). Older age groups have the highest incidence of cutaneous SCC, which is directly related to the cumulative effect of exposure to ultraviolet radiation 
were found free in 369 slides analyzed (98.7\%) and deep resection margins in 364 slides (97.3\%) (Table 1$)$.

\section{DISCUSSION}

There is a lack of literature and specific studies on CSCC. The absence of epidemiological and histopathologic data can be explained by the exclusion of non-melanoma skin cancers from cancer records or by the existence of incomplete data in relation to the disease. ${ }^{1}$ Also, when taken into consideration, SCC is grouped with BCC, which makes a deeper analysis of its features more difficult.

SCC accounted for about $20 \%$ of cases in our literature review. ${ }^{1,2,4}$ In Curitiba, the capital city of Paraná state, the rate was higher than the figures revealed by other studies: $29 \% .^{10}$ The results of the present study were inconsistent with these rates, revealing a correlation of $18.7 \%$.

In our sample, men accounted for $52 \%$ of cases in accordance with data obtained in the city of Tubarão, Santa Catarina state, and western São Paulo state. ${ }^{1,711}$ Male cases also prevailed in the southern region of Brazil: $60.1 \%$ in Curitiba and $64.89 \%$ in Blumenau. ${ }^{2,12}$ According to the literature, the male/female ratio varies by up to $4: 1{ }^{10-14}$ A possible explanation for the reasion our study be lower is probably due to the exclusion of lip SCC from this study, which represents a 4 -fold higher event rate in men. ${ }^{7,14}$

In this review, we observed the highest incidence rate of CSCC in patients older than 60 years of age. ${ }^{1,27,14}$ The sample data from this study were similar to those found by Ferreira in Taubaté
(SP), in which $57.1 \%$ of SCC cases occurred in patients older than 70 years of age. ${ }^{15}$ Nunes and Correa, both in Tubarão (SC), found a percentage of $42.9 \%$ and $45.8 \%$, respectively. ${ }^{1,7}$ In our sample, the rate was $59.7 \% .^{15}$ In agreement with other studies, the most affected age group was between 71 and 80 years, with a mean age of 71.53 years. ${ }^{714,15}$ The higher prevalence in older age groups reveals the cumulative effects of sun damage. ${ }^{1,2,4,16}$ A lower DNA repair capacity is also related to aging. ${ }^{2,4,6}$

The predominant anatomical sites were the head and neck (59\%), which is consistent with other studies. ${ }^{1,7,14-16}$ Nasser considered squamous cell carcinoma of the lip in his sample and the incidence rate for those sites was higher (78\%). Similarly, a predilection for the face, nose, ears, and scalp had been documented, corresponding to $20 \%, 15 \%, 14 \%$, and $14 \%$ respectively in that sample. ${ }^{7,8,14,16}$ The predilection for sun-exposed areas is related to the role of ultraviolet radiation in the etiology of non-melanoma skin cancer. ${ }^{24,6,15}$ According to the $17^{\text {th }}$ edition of the American Joint Committee on Cancer, primary tumors located on the ear are considered a high-risk factor. ${ }^{9}$

Although clinicians suspected malignancy in $82 \%$ of cases, we noted a difficulty in characterizing predictors of malignancy. Clinical differentiation capacity between CSCC and BCC proved to be precarious, and, in most cases, clinicians mistakenly suspected the latter. Only $15.6 \%$ of the hypotheses suggested SCC.

The present study was consistent with the literature, indicating a higher prevalence of CSCC in white-skinned populations. ${ }^{1,4,67,13}$ According to the Brazilian Institute of Geography and

TABLE 1: Histomorphological profile

\begin{tabular}{|c|c|c|c|c|c|}
\hline 1.a. Broder's grade & $\mathbf{n}$ & $\%$ & 1.f. Perineural invasion & $\mathbf{n}$ & $\%$ \\
\hline I & 146 & 39 & Present & 40 & 10.7 \\
\hline II & 200 & 53.5 & Absent & 334 & 89.3 \\
\hline III & 28 & 7.5 & Total & 374 & 100 \\
\hline Total & 374 & 100 & & & \\
\hline 1.b. Clark's level & $\mathbf{n}$ & $\%$ & 1.g. Neural invasion & $\mathbf{n}$ & $\%$ \\
\hline II & 9 & 2.4 & Present & 1 & 0.3 \\
\hline III & 16 & 4.3 & Absent & 373 & 99.7 \\
\hline IV & 282 & 75.4 & Total & 374 & 100 \\
\hline V & 67 & 17.9 & & & \\
\hline Total & 374 & 100 & & & \\
\hline 2.c. Stromal desmoplasia & $\mathbf{N}$ & $\%$ & 2.h. Angiolymphatic invasion & $\mathbf{N}$ & $\%$ \\
\hline Discrete & 179 & 66.3 & Present & 3 & 0.8 \\
\hline Moderate & 76 & 28.1 & Absent & 371 & 99.2 \\
\hline Marked & 15 & 5.6 & Total & 374 & 100 \\
\hline Total & 270 & 100 & & & \\
\hline 2.d. Nuclear pleomorphism & $\mathbf{N}$ & $\%$ & 2.i. Lateral resection margins & $\mathbf{N}$ & $\%$ \\
\hline Discrete & 24 & 8.5 & Free & 369 & 98.7 \\
\hline Moderate & 208 & 74.1 & Compromised & 5 & 1.3 \\
\hline Marked & 49 & 17.4 & Total & 374 & 100 \\
\hline Total & 281 & 100 & & & \\
\hline 2.e. Lymphocytic infiltration & $\mathbf{N}$ & $\%$ & 2.j. Deep resection margins & $\mathbf{N}$ & $\%$ \\
\hline Discrete & 126 & 43.3 & Free & 364 & 97.3 \\
\hline Moderate & 119 & 40.9 & Compromised & 10 & 2.7 \\
\hline Marked & 46 & 15.8 & Total & 374 & 100 \\
\hline Total & 291 & 100 & & & \\
\hline
\end{tabular}


Statistics, $74.8 \%$ of the population of Campos Gerais is white. ${ }^{17}$ In our study, $100 \%$ of the sample was white. In Clayman et al., in Texas, white-skinned population accounted for $97.6 \%$ of the sample. ${ }^{18}$ In a report by Ferreira et al., in Taubate (SP), $82.8 \%$ of the sample was from white skinned people. ${ }^{15}$

Although CSCC is described as a hard slow-growing tumor, often painful, with the possibility of ulceration, which is rarely pigmented, macroscopic examination revealed brownish coloration in different shades in $53.5 \%$ of the lesions. ${ }^{6}$ Therefore, color variation in the specimen caused by conservation care should be taken into consideration.

Histopathological parameters for lesion evaluation followed the College of American Pathologists protocol for CSCC. ${ }^{9}$ According to Clayman et al., lesions equal to or larger than $4 \mathrm{~cm}$ in size, displaying evidence of perineural invasion, and invasion beyond subcutaneous tissues are considered the most significant risk factors associated with CSCC-specific mortality, which can be evaluated with the previously mentioned protocol..$^{9,18}$

The average major axis found in lesions in the present study was $1.53 \mathrm{~cm}$, lower than that found in other studies: $1.9 \mathrm{~cm}$ and 3.6 cm in Tubarão (2012 and 2009); $2.0 \mathrm{~cm}$ in Texas; and $2.2 \mathrm{~cm}$ in Greece (in a small study limited to head and neck lesions). ${ }^{1,8,18}$ Only 26 cases showed lesions equal to or larger than $4 \mathrm{~cm}$ in size, which revealed low mortality risk for most lesions ( $7 \%$ ). In the study by Clayman $e t$ al., $24.8 \%$ of lesions were equal to or larger than $4 \mathrm{~cm}$ in diameter. ${ }^{18}$ In Corrêa et al., only $4.58 \%$ of cases presented with similar diameter. ${ }^{7}$

Our study revealed moderately differentiated CSCC in $53.5 \%$ of cases, well differentiated in $39.0 \%$, and poorly differentiated in $7.5 \%$. A study conducted in the Netherlands by Khanna et al. revealed that well-differentiated lesions are associated with a lower mortality rate than poorly differentiated or undifferentiated lesions. ${ }^{16}$ It is also known that these lesions have metastasis occurrence rates three times higher than moderately or well-differentiated lesions. ${ }^{19}$ Nasser, Corrêa, and Hollestein describe a predomi- nance of well-differentiated tumors in the diagnosis of cutaneous SCC: $72.9 \%, 77 \%$, and $88.8 \%$ of the cases, respectively. ${ }^{7,13,16}$

Invasion depth was measured by Clark level. In the present study, most cases (75\%) were Clark level IV (invasion into the reticular dermis). It is known that Clark level V lesions (invasion into the subcutaneous fat) have an increased potential for metastasizing. ${ }^{9,16-18}$ Clark level V - indicator of poor prognosis - was observed in $18 \%$ of the sample, a figure close to that found by Clayman et al. (2005), which was $15.5 \%{ }^{18}$

According to the author, $47.3 \%$ of cases of cutaneous SCC with perineural invasion are associated with metastasis. ${ }^{18}$ Clinically, CSCC is characterized by pain, paresthesia, anesthesia, and paresis. ${ }^{7}$ Perineural invasion was present in $11 \%$ of cases reviewed, a lower figure than the $14 \%$ revealed by the literature. ${ }^{18}$

Angiolymphatic invasion - present in only three cases $(0.8 \%)$ - is related to mortality to a large extent. ${ }^{18}$ This number is inconsistent with Clayman's et al.'s findings (2005), which was $15.5 \% .^{18}$

Deep and lateral surgical margins were referred to as free in $98 \%$ of cases. In a study conducted in Tubarão (SC), only $82 \%$ of the slides presented free margins. ${ }^{7}$

Stromal desmoplasia, nuclear pleomorphism, lymphocytic infiltration, and neural invasion were also evaluated. However, we did not find enough studies to establish data comparison.

\section{CONCLUSION}

The epidemiological and histopathological profile of cutaneous SCC in this study is predominantly male, with a mean age of 71.53 years, and located on the head and neck. Histomorphologically, we observed a higher incidence of lesions smaller than $4 \mathrm{~cm}$ in size, moderately differentiated, invading the reticular dermis. Perineural, neural, or angiolymphatic invasion rarely occurred. Thus, our study provides directions for a more effective preventive and diagnostic approach to cutaneous cancer in Campos Gerais. It also provides a better understanding of this neoplasia by showing features rarely studied before. 


\section{REFERENCES}

1. Nunes DH, Back L, Vieira e Silva R, Medeiros V de S. Incidence of squamous cell carcinoma of the skin in the city of Tubarão (SC) - Brazil in the years 2000, 2003 and 2006. An Bras Dermatol. 2009;84:482-8.

2. Alam M, Ratner D. Cutaneous squamous-cell carcinoma. N Engl J Med. 2001;344:975-83.

3. Inca.gov.br[Internet]. Instituto Nacional de Câncer José Alencar Gomes da Silva. Coordenação de Prevenção e Vigilância. Estimativa 20014: incidência de câncer no Brasil. Rio de Janeiro: INCA; 2014. [acesso 27 Mar. 2014]. Available on: http:// www.inca.gov.br/estimativa/2014/.

4. Wolff K, Goldsmith LA, Katz SI, Gilchrest BA, Paller AS, Leffell DJ. Fitzpatrick's Dermatology in general medicine. 7th. ed. New York: MacGraw-Hill; 2008.

5. Brantsch KD, Meisner C, Schönfisch B, Trilling B, Wehner-Caroli J, Röcken M, et al. Analysis of risk factors determining prognosis of cutaneous squamous-cell carcinoma: a prospective study. Lancet Oncol. 2008;9:713-20.

6. Calonje E, Brenn T, Lazar AJ, McKee PH. McKee's Pathology of the Skin. 11th ed. Philadelphia: Elsevier-Saunders; 2012.

7. Corrêa LH, Popoaski CP, Custódio G, Gonçalves CO, Trevisol FS. Epidemiology of squamous cell carcinomas among the population attended in the city of Tubarão, Brazil, between 1999 and 2009. An Bras Dermatol. 2012;87:572-7.

8. Kyrgidis A, Tzellos TG, Kechagias N, Patrikidou A, Xirou P, Kitikidou K, et al. Cutaneous squamous cell carcinoma (SCC) of the head and neck: risk factors of overall and recurrence-free survival. Eur J Cancer. 2010;46:1563-72.

9. Cap.org [Internet]. College of American Pathologists. Protocol for the examination of specimens from patients with squamous cell carcinoma of the skin. 2013 0ct;3.1.0.2 [cited 2013 Mar 23]. Available on: http://www.cap.org/apps/docs/ committees/cancer/cancer_protocols/2013/SkinSquamous_13protocol_3102. pdf.

10. Dergham AP, Muraro CC, Ramos EA, Mesquita LAF, Collaço LM. Distribuição dos diagnósticos de lesões pré-neoplásicas e neoplásicas de pele no Hospital Universitário Evangélico de Curitiba. An Bras Dermatol. 2004;79:555-9.

11. Silva AC, Tommaselli JTG, Corrêa MP. Estudo retrospectivo dos casos novos de câncer de pele diagnosticados na região oeste de São Paulo, Brasil. Hygeia. 2008;4:1-14.

12. Nasser N. Epidemiologia dos cânceres epinocelulares - Blumenau (SC) - Brasil, de 1980 a 1999. An Bras Dermatol. 2004;79:669-77

13. Zamanian A, Farshchian M, Meheralian A. A 10-year study of squamous cell carcinoma in Hamedam in the west of Iran (1993-2002). Int J Dermatol. 2006;45:37-9.

14. Staples MP, Elwood M, Burton RC, Williams JL, Marks R, Giles GG. Non-melanoma skin cancer in Australia: the 2002 national survey and trends since 1995. Med J Aust. 2006;184:6-10.

15. Ferreira FR, Nascimento LFC. Câncer cutâneo em Taubaté (SP) - Brasil, de 2001 a 2005: um estudo de prevalência. An Bras Dermatol. 2008;83:317-22.

16. Hollestein LM, de Vries E, Nijsten T. Trends of cutaneous squamous cell carcinoma in the Netherlands: increased incidence rates, but stable relative survival and mortality 1989-2008. Eur J Cancer. 2012 Sep;48:2046-53.

17. Ipardes.gov.br [Internet]. Instituto Paranaense de Desenvolvimento Econômico e Social. Cadernos Municipais 2013 [acesso 17 Mar 2014]. Available on: http:// www.ipardes.gov.br/cadernos/.

18. Clayman GL, Lee JJ, Holsinger FC, Zhou X, Duvic M, El-Naggar AK, et al. Mortality risk from squamous cell skin câncer. J Clin Oncol. 2005;23:759-65.

19. Khanna M, Fortier-Riberdy G, Dinehart SM, Smoller B. Histopathologic evaluation of cutaneous squamous cell carcinoma: results of a survey among dermatopathologists. J Am Acad Dermatol. 2003;48:721-6.

\author{
MAILING ADDRESS: \\ Fernanda Magri de Souza \\ R. Santos Dumont, 1436 \\ Centro \\ Ponta Grossa, PR - \\ Brazil \\ E-mail:fer.magri@hotmail.com
}

How to cite this article: Souza FM, Baroni VER, Montemór Netto MR. Analysis of the histomorphologic profile of invasive cutaneous squamous cell carcinoma between 2002-2011 in a pathology laboratory in the region of Campos Gerais. An Bras Dermatol. 2017;92(1):81-5. 